\title{
Standardized Precipitation Index Aplicado à Identificação do Padrão das Chuvas na Vertente Paranaense da Bacia Hidrográfica do Rio Itararé
}

\author{
Paulo Miguel de Bodas Terassi ${ }^{1}$ (D), José Francisco de Oliveira Júnior ${ }^{2,3}$ (D), Givanildo de Gois ${ }^{4}$ \\ , Emerson Galvani ${ }^{1}$ (D), Bruno Serafini Sobral ${ }^{3,5}$ (D), Vitor Hugo Rosa Biffi ${ }^{6}$ \\ ${ }^{1}$ Programa de Pós-Graduação em Geografia Física, Universidade de São Paulo, São Paulo, SP, \\ Brasil. \\ ${ }^{2}$ Instituto de Ciências Atmosféricas, Universidade Federal de Alagoas, Maceió, AL, Brasil. \\ ${ }^{3}$ Programa de Pós-Graduação em Engenharia de Biossistemas, Universidade Federal \\ Fluminense, Niterói, RJ, Brasil. \\ ${ }^{4}$ Escola de Engenharia Industrial Metalúrgica de Volta Redonda, Universidade Federal \\ Fluminense, Volta Redonda, RJ, Brasil. \\ ${ }^{5}$ Instituto de Terras e Cartografia do Estado do Rio de Janeiro, Rio de Janeiro, RJ, Brasil. \\ ${ }^{6}$ Programa de Pós-Graduação em Geografia, Universidade Estadual de Maringá, Maringá, PR, \\ Brasil.
}

Recebido em: 5 de Novembro de 2018 - Aceito em: 17 de Abril de 2019

\begin{abstract}
Resumo
Este trabalho objetiva avaliar a aplicação do Standardized Precipitation Index (SPI) para as escalas mensal (SPI-1), trimestral (SPI-3) e anual (SPI-12) para a vertente paranaense da bacia hidrográfica do rio Itararé (BHRI). Foram utilizados os dados pluviométricos de catorze postos pluviométricos obtidos do Instituto das Águas do Paraná e pelo Instituto Agronômico do Paraná para o período de 1976 a 2012 na avaliação espaço-temporal do SPI desenvolvido por McKee et al. (1993). Verificou-se que $71,1 \%$ dos anos foram categorizados como próximo ao normal (SPI-12) e, entretanto, para o período entre julho a setembro verificou-se um aumento significativo das secas na BHRI, segundo o SPI-3 e o SPI-1. No outono e inverno verificou-se a maior frequência nas categorias de seca, enquanto que na primavera predominou a normalidade e no verão as categorias úmidas foram mais expressivas. A utilização do índice SPI para diferentes escalas demonstrou que, embora a escala SPI-12 tenha predominado a categoria próxima ao normal, as escalas SPI-3 e SPI-1 mostraram com maior acurácia os períodos de maior susceptibilidade às secas na BHRI.
\end{abstract}

Palavras-chave: seca, recursos hídricos, riscos climáticos.

\section{Standardized Precipitation Index Applied to the Identification of the Rainfall Pattern in the Paraná Slope of the Itararé Watershed}

\begin{abstract}
This paper aims to evaluate the application of the Standardized Precipitation Index (SPI) for the monthly (SPI-1), quarterly (SPI-3) and annual (SPI-12) scales for Paraná slope of the Itararé watershed (PSIW). Were used the rainfall data from fourteen pluviometric stations obtained from the Paraná Water Institute and the Paraná Agronomic Institute for the period between 1976 to 2012 in the spatiotemporal evaluation of SPI developed by McKee et al. (1993). The interannual variability of SPI-12 and the relative frequency of SPI-3 and SPI-1 categories were evaluated. It was verified that $71.1 \%$ of the years were classified as close to normal and however, from July to September there was a significant increase in droughts in the PSIW according to SPI-3 and SPI-1. In the autumn and winter the highest frequency was observed in the categories of drought, whereas in the spring normality prevailed and in the summer the humid categories were more expressive. The use of the SPI index for different scales showed that although the SPI-12 scale prevailed in
\end{abstract}

Autor de correspondência: Paulo Miguel de Bodas Terassi, pmbterassi@usp.br. 
the normality category, the SPI-3 and SPI-1 scales showed more accurately the quarters and months of greater susceptibility to droughts in the PSIW.

Keywords: drought, water resources, climate risks.

\section{Introdução}

Os estudos climáticos aplicados em bacias hidrográficas têm como finalidade subsidiar o planejamento e a gestão dos recursos hídricos, a partir da sistematização do conhecimento e informações sobre as características hidrológicas (Clarke e Silva, 2004; Carmello e Sant'Anna Neto, 2017).

A seca é um dos eventos climáticos que compromete o abastecimento de água doméstico e industrial, a irrigação de culturas agrícolas, a dessedentação animal e, portanto, dada a sua severidade, pode acarretar prejuízos socioeconômicos e ambientais (Seiler et al., 2002; Zeng et al., 2008; Mishra e Singh, 2010; Blain, 2013). O monitoramento da frequência, duração e intensidade da seca é essencial na aplicação de medidas de mitigação dos efeitos decorrentes desta anomalia climática (Komuscu, 1999; Hayes, 2000; Sirdas e Zen, 2004; Turkes e Tatley, 2009).

$\mathrm{Na}$ literatura, têm sido usadas diversas metodologias, por exemplo, monitoramento da seca via produtos orbitais de satélites ambientais (Oliveira-Júnior et al., 2017), seguidos de índices de seca (Oliveira-Júnior et al., 2012; Gois et al., 2015; Rajsekharet al., 2015). Um dos índices mais utilizados para a investigação da ocorrência e magnitude das secas é o Standardized Precipitation Index (SPI) desenvolvido por McKee et al. (1993) e aperfeiçoado ao longo de décadas. O SPI quantifica o déficit ou excesso de chuva em diferentes escalas de tempo e é usado no monitoramento da duração e da intensidade de um evento extremo de seca (Agnew, 2000; Blain et al., 2010; Fernandes et al., 2010; Dai et al., 2011; Spinoni et al., 2014; Lyra et al., 2017).

Zhang et al. (2009) e Kim et al. (2014) observaram que os resultados da aplicação do SPI indicam condições de seca ou umidade excessiva e são fundamentais para o gerenciamento dos recursos hídricos. Hughes e Saunders (2002) destacam a capacidade de mensurar tais condições climáticas em diferentes escalas temporais: mensal (SPI1), trimestral (SPI-3), semestral (SPI-6) e anual (SPI-12), dezoito meses (SPI-18) e vinte e quatro meses (SPI-24).

Giddins et al. (2005) utilizaram-se de 50 anos de dados pluviométricos para aplicar o SPI em diferentes zonas climáticas do México. Eles observaram a eficácia do SPI na identificação das zonas de maior vulnerabilidade aos eventos de secas no território mexicano e ressaltaram a necessidade de compreender a frequência e magnitudes das secas a partir das características próprias à dinâmica climática de cada uma das zonas climáticas avaliadas. Ganapathi (2018) menciona a eficácia da aplicação do SPI para a comparação consistente entre diferentes localidades e domínios climáticos e sua natureza probabilística possi- bilita indicar os setores de maiores susceptibilidades às secas. Sobral et al. (2018) e Oliveira-Júnior et al. (2018) mostraram a eficácia do índice SPI para compreender a dinâmica espacial das secas intensas no estado do Rio de Janeiro em diferentes anos hidrológicos e sob a influência do modo de variabilidade climática El Niño-Oscilação Sul (ENOS) na categoria super forte.

Sousa et al. (2016) utilizaram-se do SPI para a identificação de extremos de secas e chuvas na bacia hidrográfica do Paraguaçu (BA), destacando a facilidade de aplicação do SPI na categoria de análise adotada por se utilizar apenas de dados mensais de chuva. Santos et al. (2017) estudaram o setor oriental da bacia hidrográfica do Amazonas e constataram que o uso do SPI permite o aperfeiçoamento do zoneamento agrícola, com isso auxilia na seleção de culturas de menores riscos em regiões mais apropriadas e no estabelecimento de períodos mais favoráveis de plantio e colheita.

Guedes et al. (2012) destacam que as secas ocorrem devido aos sistemas meteorológicos que atuam em determinada região, ao relevo e aos fenômenos climáticos de grande escala que definem a variabilidade e a circulação atmosférica, como por exemplo, o ENOS e o Dipolo do Atlântico para o Nordeste do Brasil (NEB), atualmente denominado Gradiente Inter-hemisférico da Temperatura da Superfície do Mar do Atlântico (GITSMA) - (Lyra et al., 2017), bem como observado por Santos et al. (2014) para o Norte do Brasil e Fechine et al. (2015) para a Região Metropolitana de Fortaleza. Nascimento et al. (2017) destacam a eficiência da utilização do SPI para a identificação espaço-temporal das secas no Maranhão bem como o desempenho do ENOS para a ocorrência das maiores anomalias de chuva no setor norte deste estado.

Li et al. (2008) avaliaram a evolução das secas na região Sul da Amazônia e identificaram uma redução de 0,32 do SPI por década, sendo associada à ação do desmatamento. Penalba e Ribeira (2016) discorrem que o SPI é eficiente e apropriado para a definição e monitoramento de secas na região Sul da América do Sul (AS). Rivera e Penalba (2014) descrevem que os eventos de La Niña de 1966, 1971-1972 e 1988-1989 foram os mecanismos de grande escala de maior influência na ocorrência de secas no Sul da AS, especialmente no ciclo 1988-1989, no qual $45 \%$ da área total em estudo estiveram em condições de seca severa.

Entretanto, os resultados obtidos por Terassi et al. (2018) mostraram que os parâmetros estatísticos (correlações de Kendall, Spearman e Pearson) empregados indicaram predominantemente baixas correlações entre o SPI e as anomalias do ENOS na região Norte do estado do 
Paraná (RNPR). Para o estado do Mato Grosso do Sul (MS), Teodoro et al. (2015) observaram a ocorrência frequente de meses categorizados como moderadamente úmido em episódios de La Niña forte e moderadamente seco em episódios de El Niño moderado ou forte. Isto é condizente com o observado por Blain e Kayano (2011), uma vez que estes autores asseguram que o ENOS não apresenta uma influência significativa para a variabilidade do SPI-1 em Campinas (SP).

A área em estudo deste trabalho teve suas características pluviométricas estudada por Terassi et al. (2017), que observaram a relação direta entre a disposição latitudinal da vertente paranaense da bacia hidrográfica do rio Itararé (BHRI) com a transição climática entre os domínios climáticos tropical e subtropical, e destacaram o desempenho do relevo e dos processos orográficos na distribuição espacial das chuvas. Considerando a ausência de investiga-

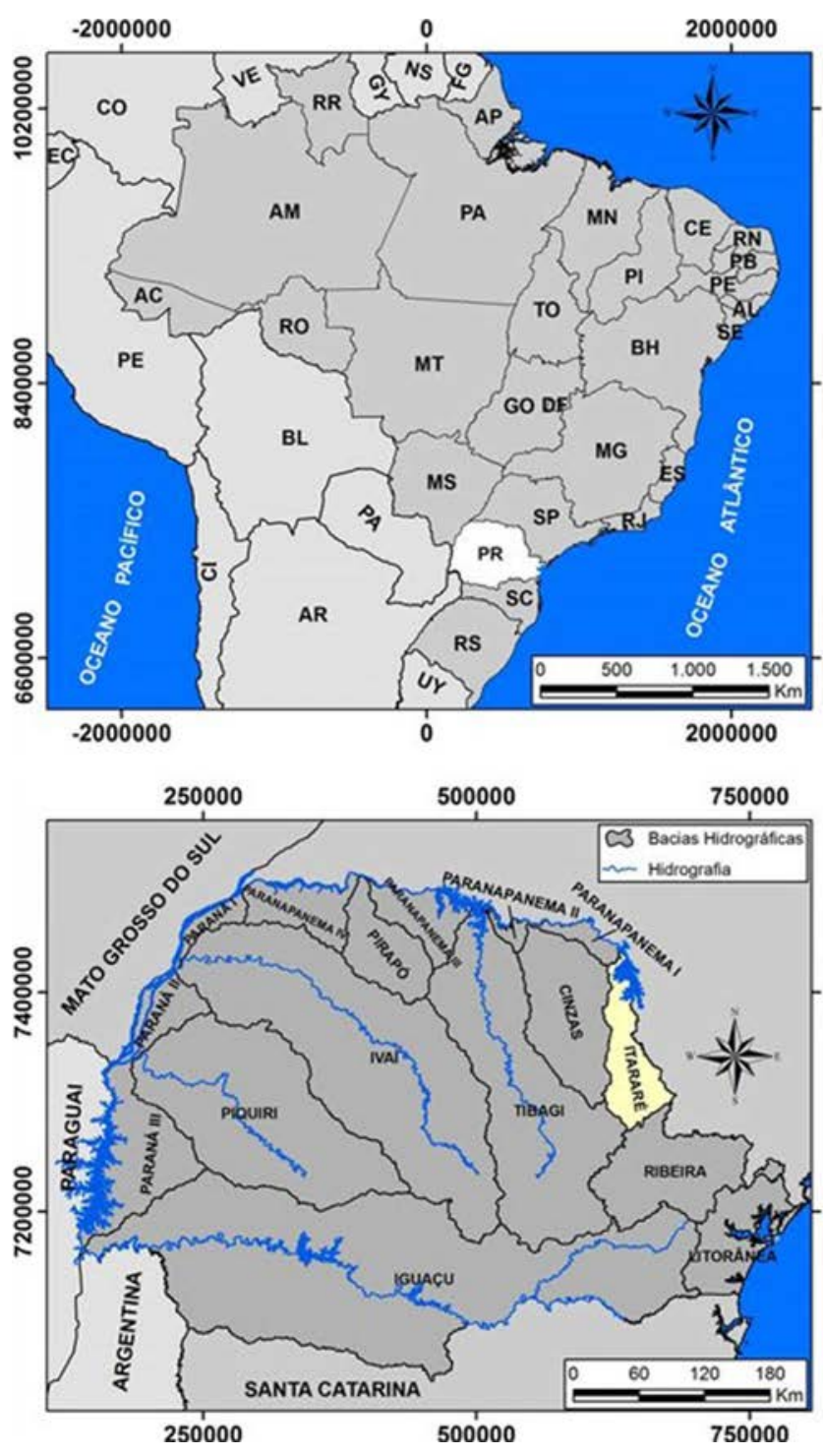

ções dos períodos de seca ou chuva excessiva, este trabalho objetiva avaliar a aplicação do Standardized Precipitation Index (SPI) nas escalas anual (SPI-12), semestral (SPI-6), trimestral (SPI-3) e mensal (SPI-1) para a vertente paraense da bacia hidrográfica do rio Itararé em uma série histórica entre os anos de 1976 a 2012.

\section{Materiais e Métodos}

\subsection{Localização e característica da área de estudo}

A área de estudo corresponde ao setor paranaense da BHRI, abrange uma superfície aproximada de $4.845 \mathrm{~km}^{2}$ (ITCG, 2018) e localiza-se no setor nordeste (NE) do estado do Paraná (Fig. 1).

Segundo Terassi e Tommaselli (2015), os setores oeste (W) e central (C) da BHRI, de maiores altitudes, são

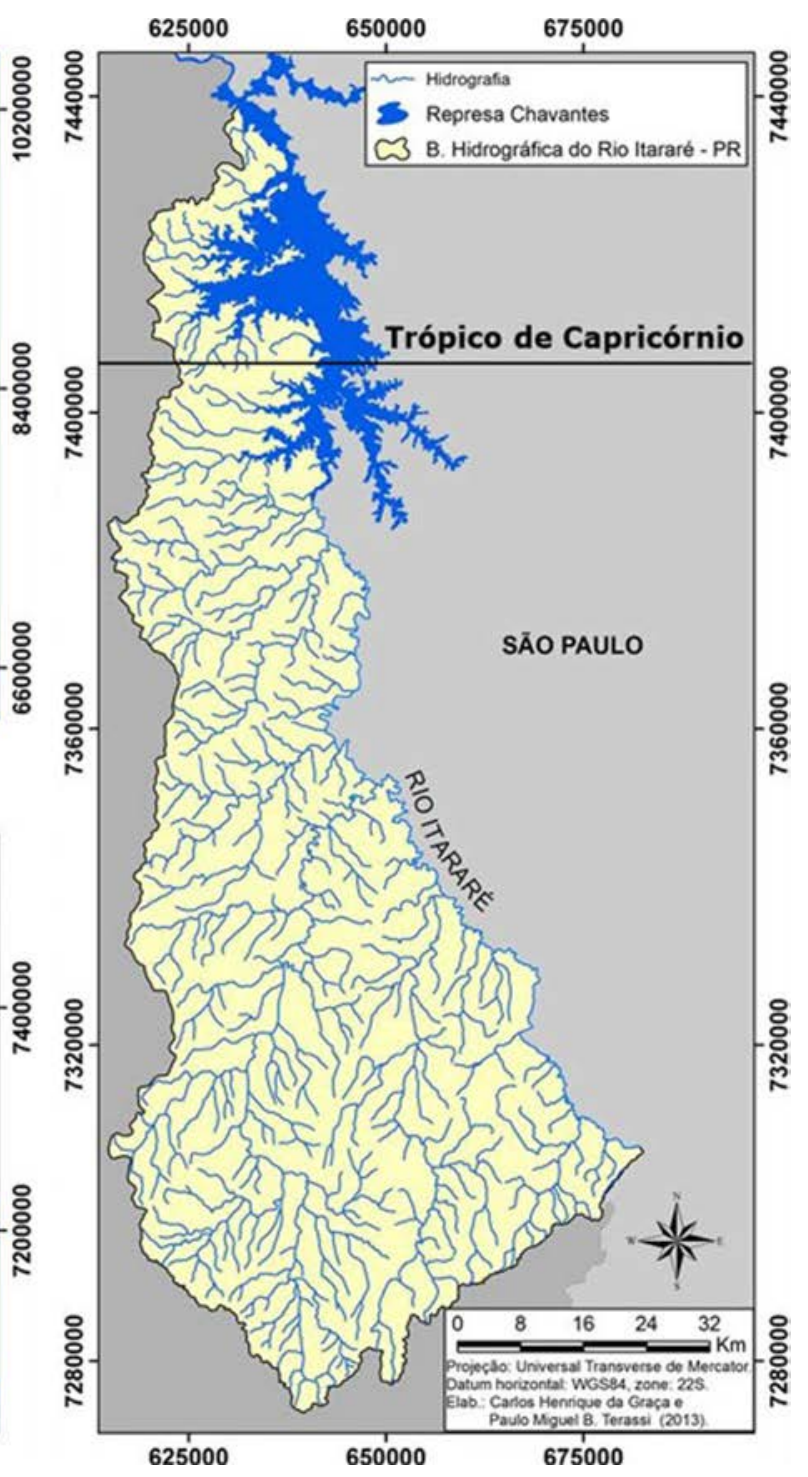

Figura 1 - Localização da vertente paranaense da bacia hidrográfica do rio Itararé. 
caracterizados pelo clima subtropical mesotérmico úmido ("Cfb"), com a temperatura média do mês mais frio inferior a $18{ }^{\circ} \mathrm{C}$, e a temperatura do mês mais quente inferior a $22{ }^{\circ} \mathrm{C}$. O setor norte $(\mathrm{N})$, com as maiores temperaturas, apresenta a tipologia climática "Cfa", a qual designa um clima subtropical quente úmido, com a temperatura do mês mais frio menor que $18{ }^{\circ} \mathrm{C}$, enquanto que durante o mês mais quente excede os $22{ }^{\circ} \mathrm{C}$. Verificaram ainda a ocorrência de chuvas em todos os meses do ano e a ausência de estação seca definida em toda a área. Estas classificações climáticas designadas pelos autores supracitados estão em conformidade às obtidas por Álvares et al. (2013), Aparecido et al. (2016) e Dubreuil et al. (2017) para esta área de estudo dentro do território brasileiro e paranaense.

\subsection{As séries pluviométricas}

No estudo foram obtidos dados de treze postos pluviométricos gerenciados pelo Instituto das Águas do Paraná e da estação meteorológica da rede do Instituto Agronômico do Paraná (IAPAR) para o período de 1976 a 2012. Os postos pluviométricos situados no entorno da área de estudo foram selecionados para melhor avaliação temporal/espacial do SPI, além da utilização para preenchimentos de falhas (Tabela 1).

Para a seleção de postos pluviométricos representativos da área de estudo, recorreu-se à utilização das regiões pluviométricas homogêneas determinadas por Terassi et al. (2016) (Fig. 2). Para uma análise detalhada da variabilidade interanual do índice SPI-12 e da frequência relativa de ocorrências das categorias de SPI-3 e SPI-1, foram selecionados os postos pluviométricos de Joaquim Távora,
Piraí do Sul, São José da Boa Vista e Doutor Ulysses (Varzeão), pois estes apresentaram o menor número de falhas em suas respectivas regiões pluviométricas.

Todas as análises estatísticas foram feitas no software ambiente $\mathrm{R}$ versão 3.3.2 ( $\mathrm{R}$ Development Core Team, 2016).

\subsection{O índice SPI}

De acordo com McKee et al. (1993) a série histórica é ajustada a uma distribuição de probabilidade gama, na qual é transformada em uma distribuição normal, onde o índice SPI para cada localidade e período desejado tem o valor zero para sua média e variância unitária. A distribuição gama é definida pela função de densidade de probabilidade (FDP) (Eq. (1)):

$$
f(x)=\frac{1}{\Gamma(\alpha) \beta^{\alpha}} x^{\alpha-1} e^{\frac{-x}{\beta}}
$$

em que $\alpha>0(\alpha)=$ parâmetro de forma (adimensional); $\beta>0(\beta)=$ parâmetro de escala $(\mathrm{mm}) ; \mathrm{x}>0(\mathrm{x})=$ total de chuva (mm); $\Gamma(\alpha)=$ função gama definida pela Eq. (2):

$$
\Gamma(\alpha)=\int_{0}^{\infty} x^{\alpha-1} e^{-x} d x
$$

Os parâmetros e a função de densidade de probabilidade gama foram ajustados para distribuição de frequência dos totais de chuvas dos quatro postos pluviométricos. Foram calculados os parâmetros de forma $(\alpha)$ e escala $(\beta)$, da função de densidade de probabilidade gama estimada para cada uma das estações na escala anual. Segundo OliveiraJúnior et al. (2012) e Gois et al. (2015) o Método da Má-

Tabela 1 - Região homogênea(RH), conforme definição de Terassi et al. (2017), identificação (ID) localização geográfica, altitude e falhas de registros

\begin{tabular}{|c|c|c|c|c|c|c|}
\hline RH & ID & Postos pluviométricos & $\mathrm{X}(\mathrm{Nm})$ & $\mathrm{Y}(\mathrm{Em})$ & $\begin{array}{l}\text { Altitude } \\
\text { (m) }\end{array}$ & $\begin{array}{r}\text { Falhas } \\
(\%)\end{array}$ \\
\hline \multirow[t]{5}{*}{ I } & 1 & Carlópolis (Nova Brasília) & 7395526 & 627900 & 563 & 0 \\
\hline & 6 & Joaquim Távora & 7400672 & 615718 & 512 & 0 \\
\hline & 9 & Ribeirão Claro & 7433790 & 627919 & 782 & 0 \\
\hline & 10 & Santana do Itararé & 7372279 & 640380 & 543 & 0 \\
\hline & 11 & São José da Boa Vista & 7354589 & 637409 & 550 & 0,22 \\
\hline \multirow[t]{4}{*}{ II } & 5 & Jaguariaíva & 7317956 & 630287 & 890 & 0,22 \\
\hline & 12 & São José da Boa Vista (Barra Mansa) & 7337733 & 637247 & 850 & 1,98 \\
\hline & 13 & Sengés & 7333850 & 655848 & 650 & 1,13 \\
\hline & 14 & Tomazina & 7371211 & 606992 & 483 & 1,80 \\
\hline \multirow[t]{4}{*}{ III } & 2 & Castro (Fazenda Marão) & 7275043 & 633292 & 1100 & 2,95 \\
\hline & 4 & Jaguariaíva (Eduardo Xavier da Silva) & 7302629 & 643698 & 1000 & 0,92 \\
\hline & 7 & Piraí do Sul & 7286806 & 608541 & 1068 & 0 \\
\hline & 8 & Piraí do Sul (Capinzal) & 7289831 & 629085 & 1026 & 0 \\
\hline PPA & 3 & Doutor Ulysses (Varzeão) & 7282084 & 660061 & 818 & 0,22 \\
\hline
\end{tabular}
(\%) dos postos pluviométricos na BHRI. 


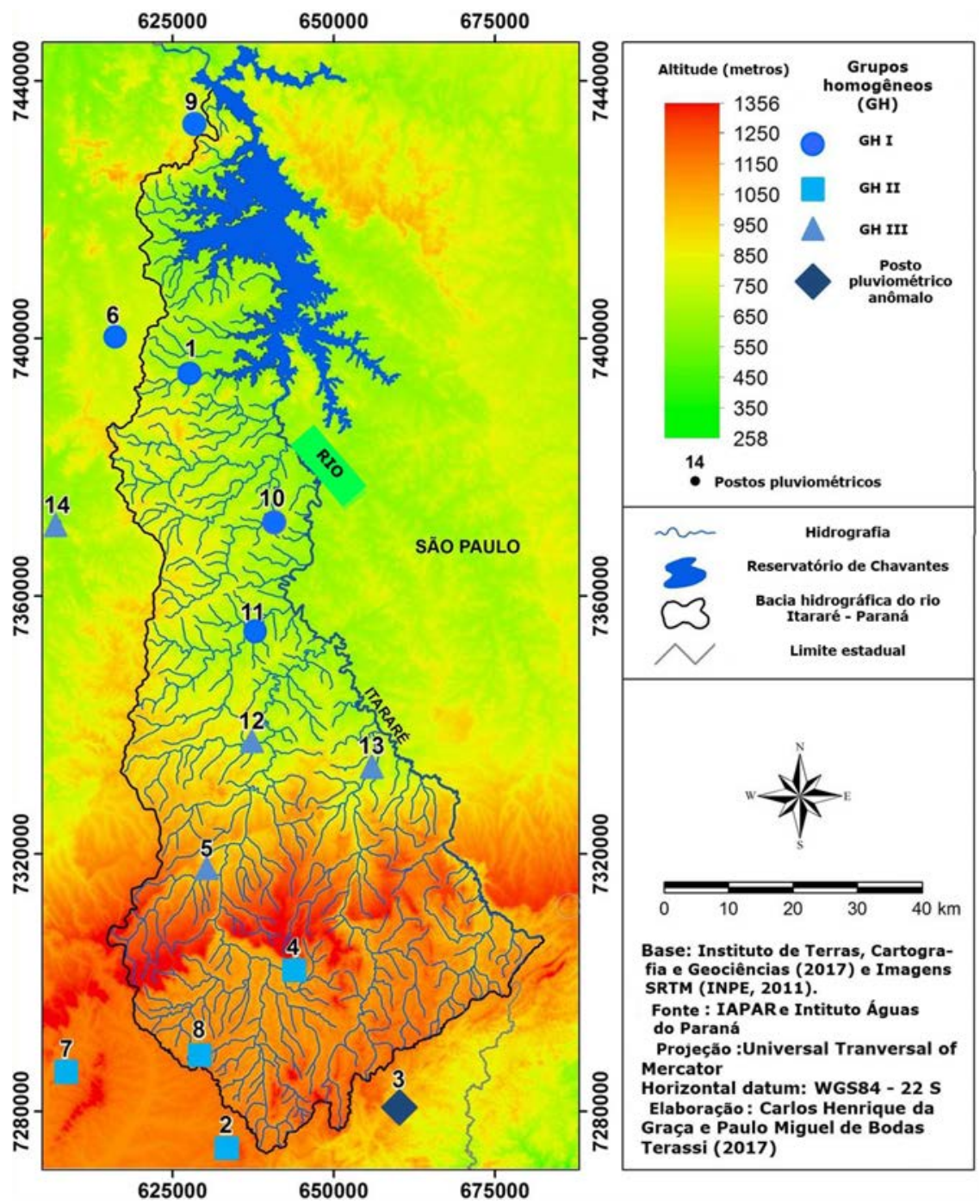

Figura 2 - Localização dos grupos homogêneos (GH I, GH II e GH III) e o posto pluviométrico anômalo na BHRI.

xima Verossimilhança (MMV) é o mais indicado para as estimativas dos parâmetros de $\alpha$ e $\beta$ (Eqs. (3) e (4)):

$$
\begin{gathered}
\alpha=\frac{1}{4 \mathrm{~A}}\left(1+\sqrt{1+\frac{4 \mathrm{~A}}{3}}\right) \\
\frac{\beta=\hat{x}}{\alpha}
\end{gathered}
$$

em que $A$ é definido pela Eq. (5):

$$
A=\ln (\bar{x})-\frac{1}{N} \sum_{i=1}^{N} \ln \left(x_{i}\right)
$$

em que $\bar{X}$ é a média da chuva (mm), Lné o logaritmo neperiano, Né número de observações.

Os parâmetros $\alpha$ e $\beta$ foram calculados para encontrar a probabilidade cumulativa de um evento de chuva observado para a escala anual. Em que a probabilidade cumula- tiva (Eqs. (5) e (6)):

$$
\mathrm{F}(x)=\int_{0}^{x} f(x) d x=\frac{1}{\Gamma(\alpha) \beta^{\alpha}} \int_{0}^{x} x^{\alpha-1} e^{\frac{-x}{\beta}} d x
$$

Mais detalhes das probabilidades cumulativas empíricas encontram-se em Oliveira-Júnior et al. (2012) e Gois et al. (2015). Após o cálculo do SPI, determinou-se para a escala mensal a frequência em número de meses das categorias descritas pelos intervalos deste índice (Tabela 2), conforme os parâmetros estabelecidos por McKee et al. (1993).

Os gráficos da distribuição interanual do SPI-12 foram realizados no software ambiente R versão 3.3.2. Os resultados do índice SPI e os gráficos de frequência relativa do SPI-3 e SPI-1 foram feitos pela planilha eletrônica Microsoft Excel. 
Tabela 2 - Classificação dos períodos secos e úmidos do SPI, segundo McKee et al. (1993).

\begin{tabular}{lc}
\hline SPI & Categorias \\
\hline$\geq 2,00$ & Extremamente úmido \\
1,50 a 1,99 & Muito úmido \\
1,00 a 1,49 & Moderadamente úmido \\
0,99 a $-0,99$ & Próximo ao normal \\
$-1,00$ a $-1,49$ & Moderadamente seco \\
$-1,50$ a $-1,99$ & Muito seco \\
$\leq-2,00$ & Extremamente seco \\
\hline
\end{tabular}

\section{Resultados e Discussão}

\subsection{Características pluviais anuais e mensais do BHRI}

A Fig. 3 representa a distribuição anual da chuva nos grupos homogêneos $(\mathrm{GH})$ da BHRI. O setor de menores totais anuais de chuva corresponde ao GH I (1367,2 mm) (Fig. 3a), no qual se atribui às menores altitudes $(<600 \mathrm{~m})$ e sua condição de características aproximadas ao domínio

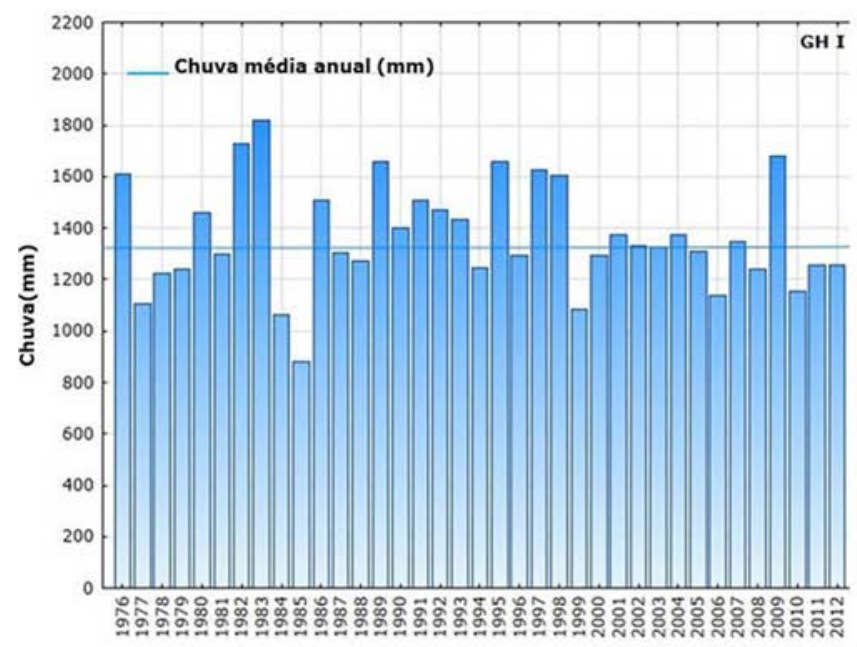

do clima tropical do Brasil Central, com uma maior concentração das chuvas nos meses correspondentes às estações do verão e primavera (Silva et al., 2006; Reboita et al., 2010; Zandonadi et al., 2015). Com as maiores altitudes $(>1000 \mathrm{~m})$, o GH III apresenta maior registro de chuva (1457,4 mm) - (Fig. 3b) em relação ao GH I justamente por apresentar menores totais de pluviosidade nos meses de verão devido às menores temperaturas e o menor potencial convectivo das chuvas (Terassi e Tommaselli, 2017) e, como característica singular, caracteriza-se por maiores médias nos meses de inverno por sua maior similaridade com as características do clima subtropical (Keller Filho et al., 2005; Nery, 2006; Wrege et al., 2016).

Em uma condição intermediária das altitudes predominantes em relação aos GH I e GH III e em transição ao domínio climático subtropical e tropical, o GH II mostrou os maiores totais de chuva $(1489,3 \mathrm{~mm})$, especialmente pelas condições térmicas possibilitarem o maior potencial de processos convectivos e produção de chuvas no período do verão (Terassi e Tommaselli, 2017) (Fig. 3c). Por sua vez, o posto pluviométrico anômalo

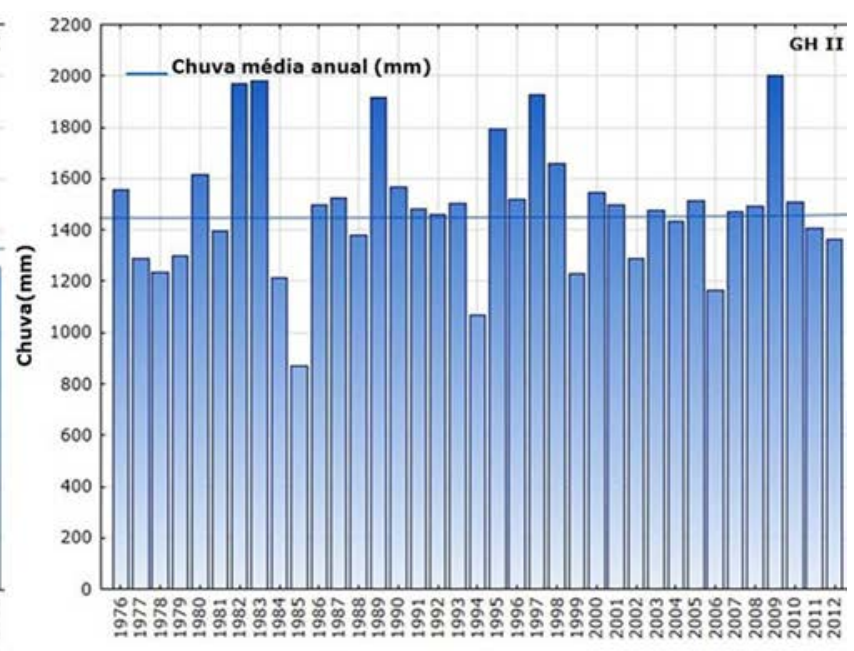

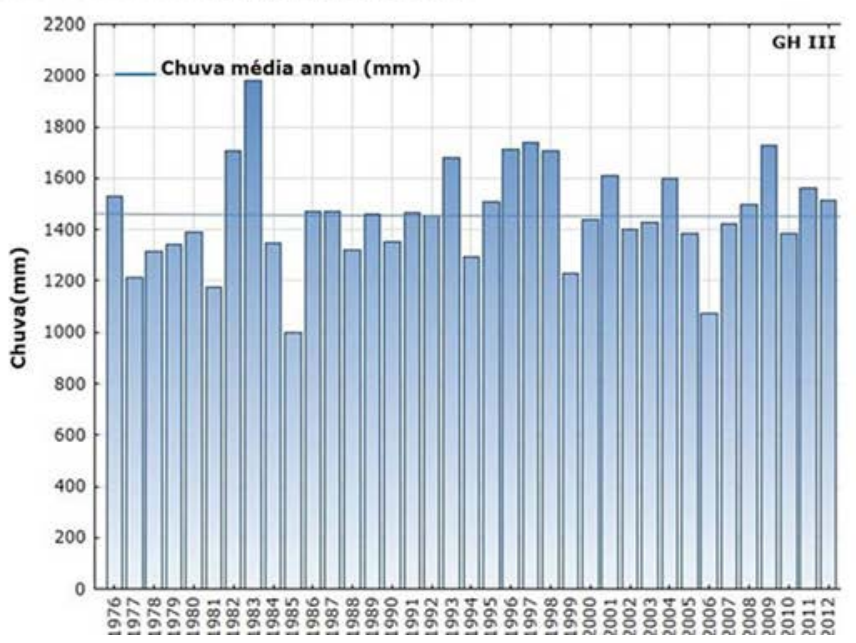

Figura 3 - Distribuição anual da chuva (mm) para os grupos homogêneos (GH I, II e III) na BHRI. 
(PPA) de Doutor Ulysses (Varzeão) distinguiu-se pelo maior total anual de pluviosidade (1787,6 mm) - (Fig. 4) por situar-se em uma condição limite do efeito orográfico $(818 \mathrm{~m})$ e, ainda corrobora com estudos realizados anteriormente, em que os maiores totais de chuva ocorrem a até aproximadamente $900 \mathrm{~m}$ de altitude (Candido e Nunes, 2008; Pellegatti e Galvani, 2010; Chierice e Landim, 2014; Correa e Galvani, 2017; Terassi e Galvani, 2017; Terassi et al., 2017).

A característica de distribuição espacial das chuvas na BHRI está em acordo com os estudos anteriores para o estado do Paraná (Cavaglione et al., 2000; Fritzsons et al., 2011). Quanto aos aspectos temporais, observa-se que os anos de maiores alterações dos totais anuais estiveram influenciados pelas fases dos ENOS, concordante ao observado por Grimm et al. (1998), Grimm et al. (2000), Nery et al. (2005), Nery e Carfan (2014) e Tedeschi et al. (2015) para a região Sul do Brasil. Os anos de 1982, 1983, 1997, 1998 e 2009 estiveram em condições de El Niño (NOAA, 2016) e obtiveram um aumento superior a $20 \%$ em todos os grupos homogêneos, com destaque para os 4169,9 mm registrados no PPA no ano de 1983, o que apresentou os maiores desvios pluviométricos em toda área em estudo. Por sua vez, os anos de 1985 e 1999 mostraram a influência significativa da fase La Niña (NOAA, 2016) devido à redução superior a $15 \%$ dos totais anuais de chuva em toda área de estudo. Estes resultados são concordantes ao observado por Terassi et al. (2017) para a unidade hidrográfica Pirapó, Paranapanema III e IV, situa- da no norte do Paraná, uma vez que estes autores verificaram desvios semelhantes para os anos destacados anteriormente.

A BHRI caracteriza-se pela concentração das chuvas entre setembro e março, período que ocorrem as médias superiores a $100 \mathrm{~mm}$ e cerca de $70 \%$ dos totais anuais e, inversamente, entre abril e agosto, que concentram aproximadamente $30 \%$ das chuvas. Estas são características próprias às regiões de clima tropical do Brasil Central, conforme apontam Silva et al. (2006) e Reboita et al. (2010) e Silva et al. (2015), especialmente no GH I, setor da área em estudo na qual se observa a maior redução de chuva nos meses de inverno, especialmente em agosto $(51,1 \mathrm{~mm})$.

Entretanto, observa-se que os setores meridionais (GH II e PPA), em função de sua maior proximidade ao domínio climático subtropical (Fritzsons et al., 2011; Wrege et al., 2016), apresentam a menor diminuição no período menos chuvoso e maior regularidade na variação da chuva ao longo do ano em relação aos demais setores da área em estudo. O PPA caracteriza-se pelos maiores totais de chuva em todos os meses, por conta do efeito orográfico (Fig. 5).

Destaca-se que há uma menor diferença dos totais de chuva entre os grupos homogêneos, especialmente em julho e agosto, meses nos quais a geração das chuvas se restringe apenas a passagem de Sistemas Frontais (SF) (Cardozo et al.,2015; Borsato e Mendonça, 2015). Nos meses de verão, nos setores de maiores temperaturas apre-

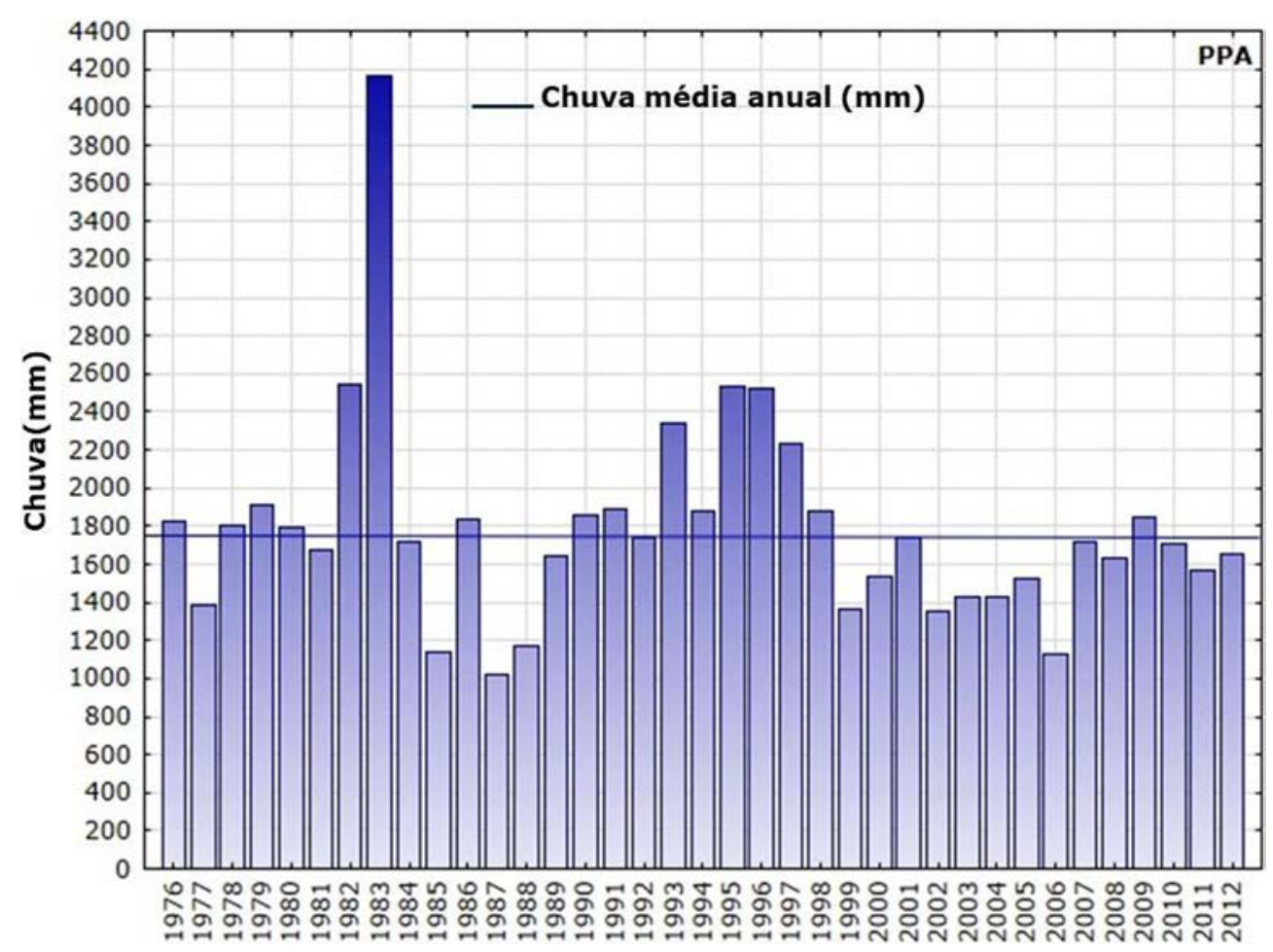

Figura 4 - Distribuição anual da chuva (mm) para o posto pluviométrico anômalo (PPA) na BHRI. 


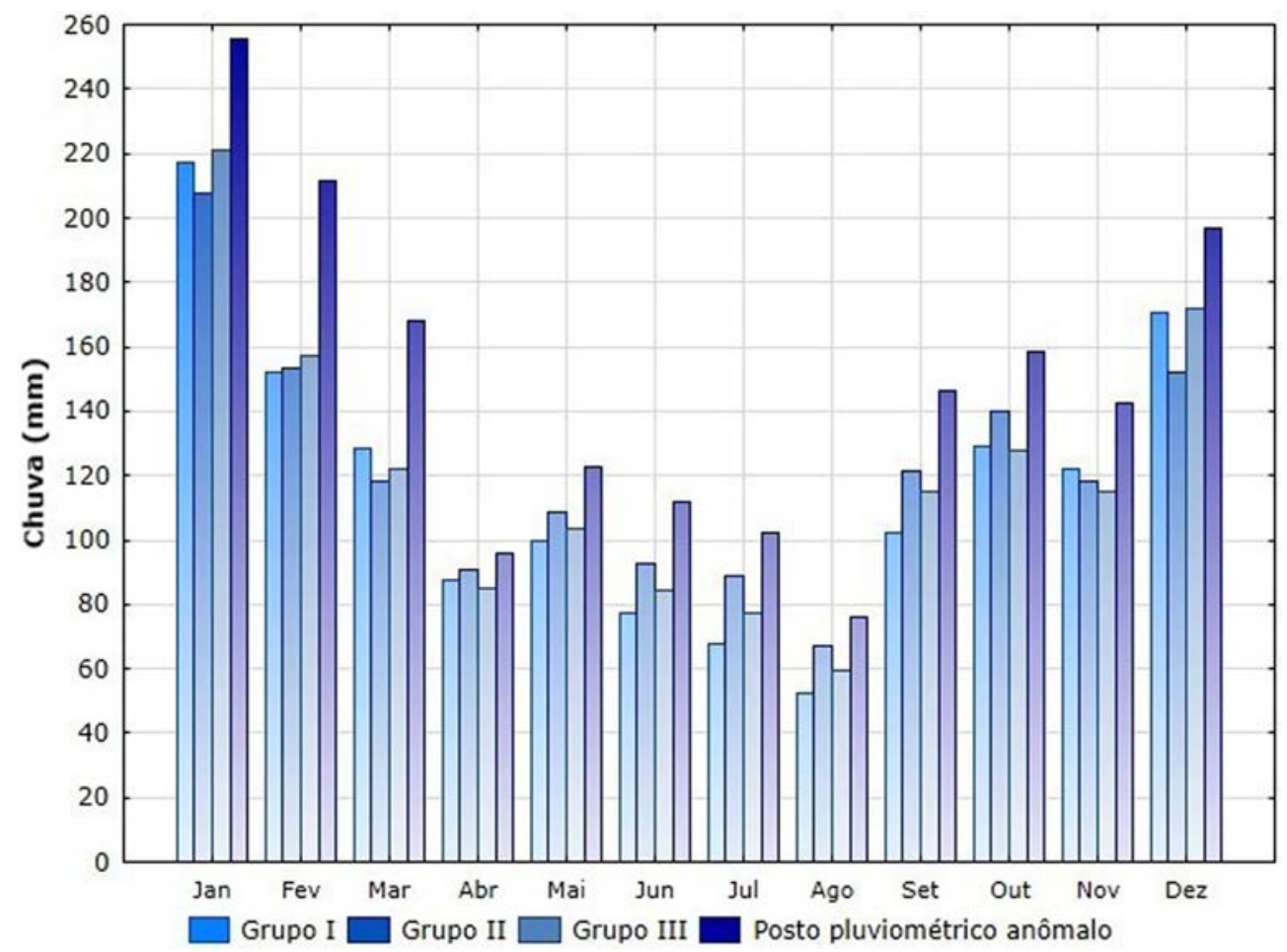

Figura 5 - Distribuição mensal da chuva (mm) na BHRI.

sentam o aumento significativo nos totais de chuva, pois além do maior potencial convectivo (Terassi e Tommaselli, 2017), verifica-se a maior atuação dos mecanismos intertropicais na formação das chuvas, como, por exemplo, a ZCAS (Zona de Convergência do Atlântico Sul), os Complexos Convectivos de Mesoescala (CCM's), as linhas de instabilidade (LI) e a massa Equatorial continental (mEc) - (Silva et al., 2006; Reboita et al., 2010; Zandonadi et al., 2015).

\subsection{SPI-12 na BHRI}

Os resultados dos índices SPI-12 indicaram que a BHRI apresentou o predomínio de anos de chuva próxima ao normal. A categoria próxima ao normal obteve $71,1 \%$ dos anos da série histórica. Vale destacar que os resultados corroboram com aqueles obtidos anteriormente por Fritz- sons et al. (2011) e Nery e Carfan (2014) no que se refere à variabilidade interanual da chuva na região Sul $(\mathrm{CV} \approx 20-25 \%)$ em relação às demais regiões do território brasileiro. As categorias "moderadamente seco" e "moderadamente úmido" se sobressaíram em relação às categorias "extremamente úmido/seco" e "muito úmido/seco", o que demonstra a baixa variação do SPI-12 na BHRI (Tabela 3). Estes resultados validam os obtidos por Teodoro et al. (2015) para o estado do Mato Grosso do Sul e Terassi et al. (2018) para a RNPR.

A baixa variabilidade interanual da chuva para a vertente paranaense da BHRI foi verificada pelo SPI- 12 . Valores iguais ou inferiores $-2,00$ foram observados apenas para o ano de 1999, que esteve sob a atuação de La Niña forte e durante a fase fria da Oscilação Decadal do Pacífico (ODP), somente para o posto pluviométrico de

Tabela 3 - Frequência relativa (\%) do SPI-12 para a BHRI.

\begin{tabular}{lcccccccccccccc}
\hline Categorias & \multicolumn{10}{c}{ Postos pluviométricos e estação meteorológica } \\
\cline { 2 - 13 } & 01 & 02 & 03 & 04 & 05 & $06^{*}$ & 07 & 08 & 09 & 10 & 11 & 12 & 13 & 14 \\
\hline Extremamente úmido & 5,4 & 5,4 & 2,7 & 5,4 & 5,4 & 5,4 & 5,4 & 5,4 & 2,7 & 5,4 & 5,4 & 5,4 & 5,4 & 5,4 \\
Muito úmido & 0,0 & 2,7 & 8,1 & 0,0 & 2,7 & 2,7 & 0,0 & 0,0 & 5,4 & 0,0 & 0,0 & 2,7 & 2,7 & 0,0 \\
Moderadamente úmido & 5,4 & 8,1 & 2,7 & 5,4 & 8,1 & 2,7 & 5,4 & 10,8 & 10,8 & 10,8 & 8,1 & 2,7 & 10,8 & 10,8 \\
Próximo ao normal & 70,3 & 67,6 & 70,3 & 78,4 & 70,3 & 75,7 & 75,7 & 67,6 & 64,9 & 64,9 & 75,7 & 75,7 & 70,3 & 67,6 \\
Moderadamente seco & 10,8 & 8,1 & 13,5 & 8,1 & 10,8 & 2,7 & 10,8 & 10,8 & 5,4 & 13,5 & 5,4 & 8,1 & 5,4 & 10,8 \\
Muito seco & 8,1 & 5,4 & 0,0 & 0,0 & 2,7 & 10,8 & 2,7 & 2,7 & 10,8 & 5,4 & 5,4 & 5,4 & 5,4 & 5,4 \\
Extremamente seco & 0,0 & 2,7 & 2,7 & 2,7 & 0 & 0 & 0 & 2,7 & 0 & 0 & 0 & 0 & 0 & 0 \\
\hline
\end{tabular}



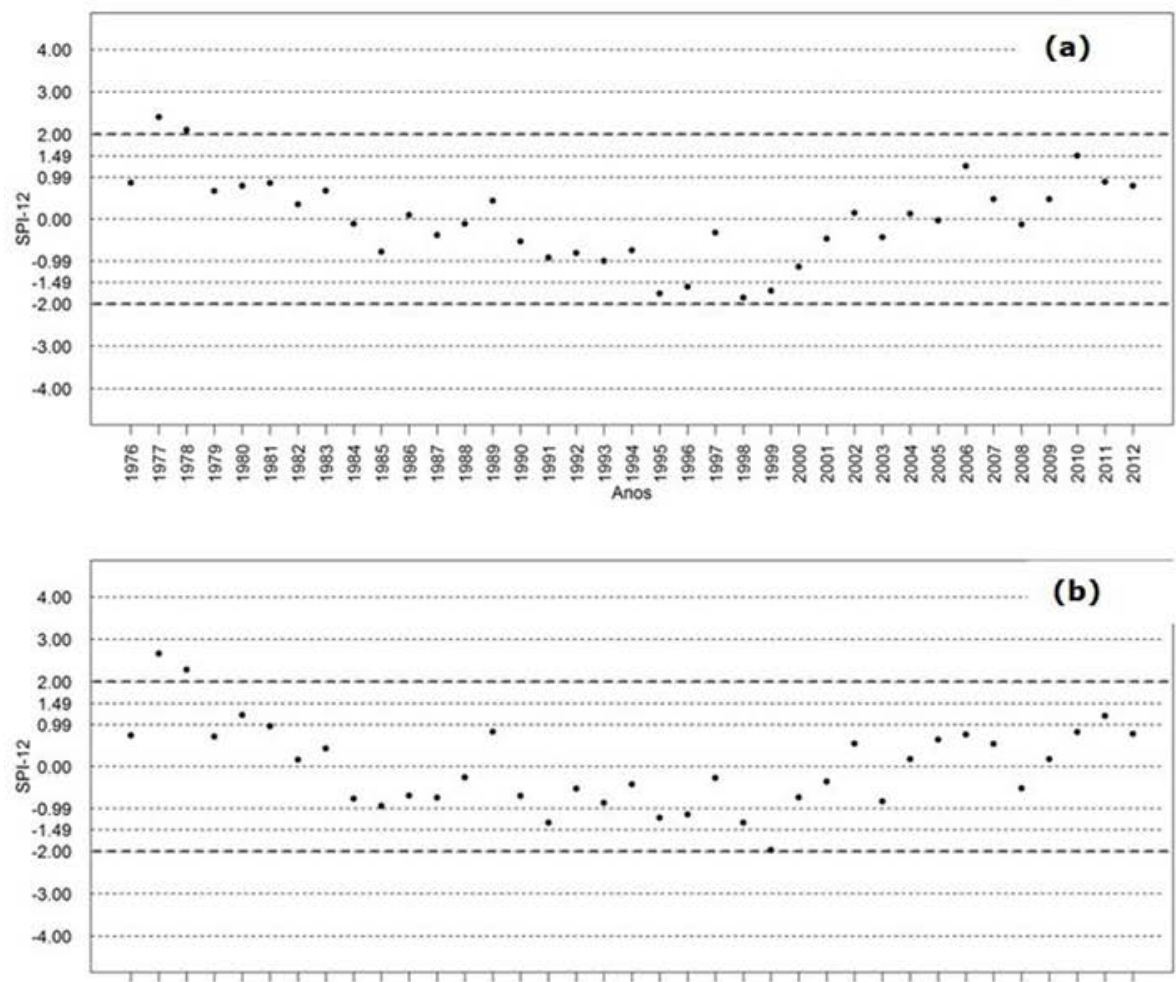

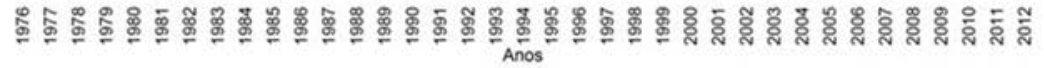

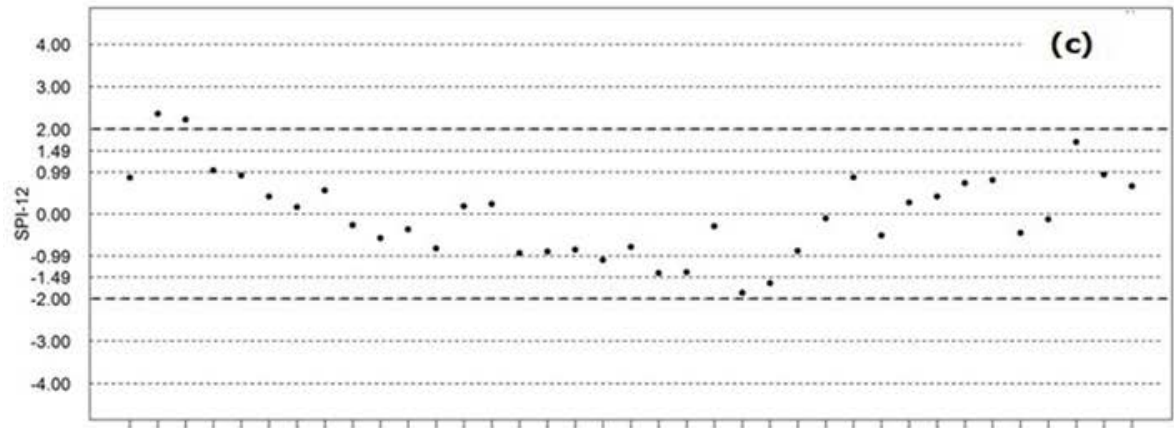

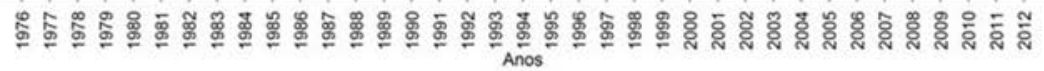

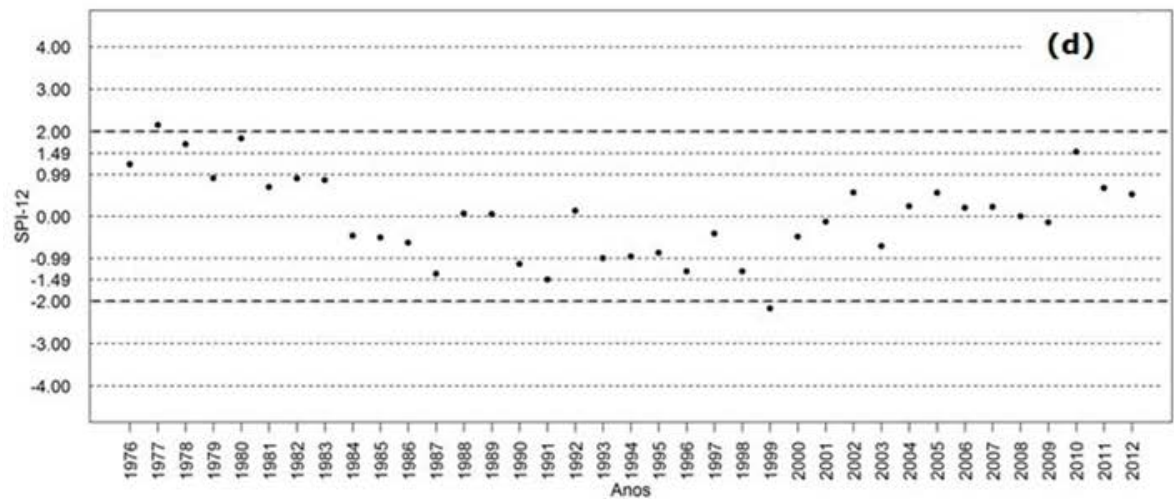

Figura 6 - Distribuição interanual do índice SPI-12 para as localidades de Joaquim Távora (a), Piraí do Sul - Capinzal (b), São João da Boa Vista (c) e Doutor Ulysses (d). 
Doutor Ulysses. Ainda nos anos de 1977 e 1978 foram obtidos valores $\geq 2,00$, com a ocorrência de El Niño fraco durante a fase quente da ODP (Nascimento Júnior e Sant'Anna Neto, 2015; NOAA, 2016), para Joaquim Távora, Piraí do Sul - Capinzal e São João da Boa Vista (Fig. 6). As exceções foram os anos de 1995, 1996, $1998 \mathrm{e}$ 1999, que apresentaram frequências nas categorias iguais ou inferiores $-0,99$, sendo que destes somente o ano de 1998 esteve sob as condições de El Niño durante os cinco primeiros meses e passou a ser influenciado pela La Niña durante os seis últimos meses deste ano, ao passo que os demais anos mostraram resultados justificáveis pela fase La Niña (NOAA, 2016; Terassi et al., 2018). Os anos de 1977 (El Niño fraco), 1978 (Neutro), 1980 (Neutro) e 2010 (El Niño e La Niña) mostraram SPI igual ou superior a 0,99 (Fig. 6).

Portanto, verifica-se uma baixa associação entre a variabilidade anual do SPI e as fases dos ENOS para a BHRI, similar ao observado por Terassi et al. (2018) para a região Norte do Paraná, mostrando-se ineficaz na distinção de anos secos e chuvosos para este setor do território brasileiro. Isto se contrapõe aos resultados para a região Nordeste e Norte do Brasil, nas quais OliveiraJúnior et al., (2012), Guedes et al. (2012) e Santos et al. (2017) mostraram elevada correlação entre a variação do

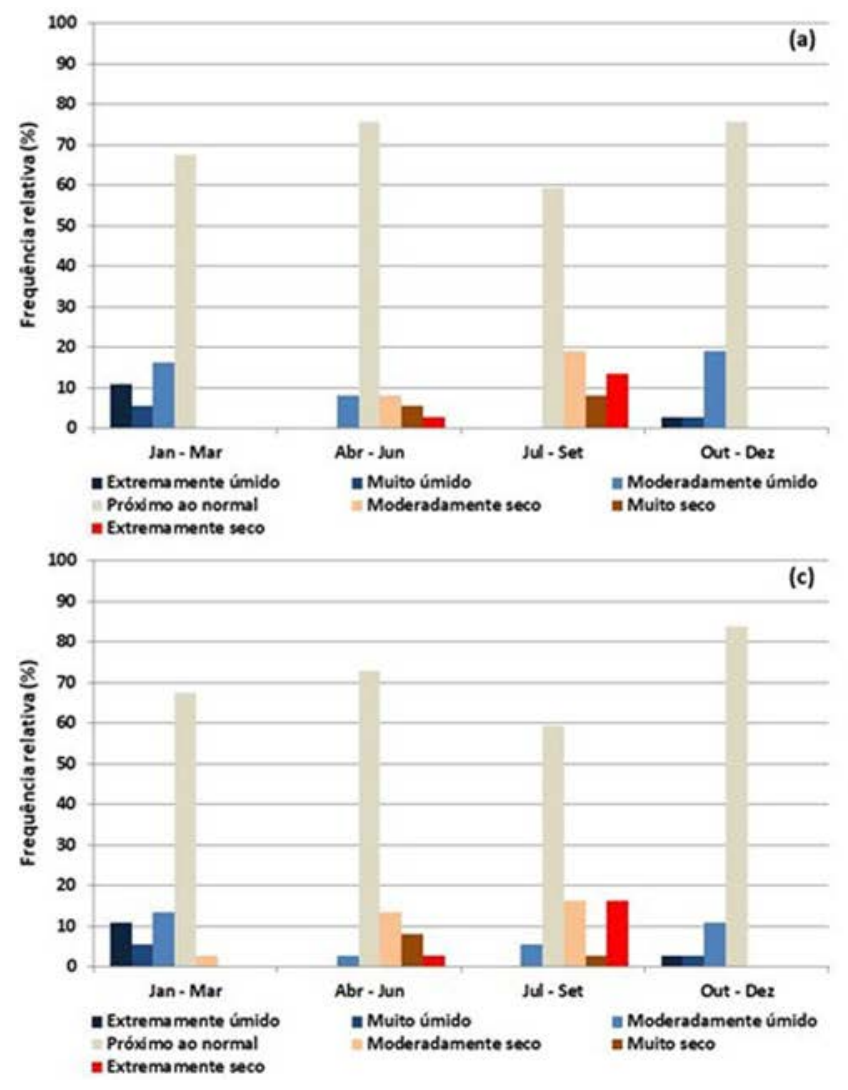

SPI-12 com as anomalias de temperatura dos Oceanos Atlântico e Pacífico Equatorial. Sobral et al. (2018) observaram a relevância dos episódios mais intensos de ENOS para a variação espaço-temporal do SPI para o estado do Rio de Janeiro.

\subsection{SPI-3 e SPI-1na BHRI}

Os índices SPI-3 e SPI-1 obtiveram resultados concordantes com as características da distribuição sazonal e mensal da chuva para a região em estudo (Figs. 7 e 8). Os trimestres de janeiro a março e outubro a dezembro (verão e primavera) apresentaram uma maior frequência nas categorias "extremamente úmido", "muito úmido" e "moderadamente úmido", segundo Terassi et al. (2016), que corresponde ao período de concentração de aproximadamente $65 \%$ dos totais anuais de chuva. Inversamente, de abril a junho e julho a setembro ocorre uma maior frequência de meses classificados nas categorias "extremamente seco", "muito seco" e "moderadamente seco", o que se deve à redução significativa das chuvas, dada a influência do clima tropical do Brasil Central (Nery, 2006; Silva et al., 2006; Wrege et al., 2016).

A análise do SPI-3 permitiu identificar padrões temporais associados à frequência relativa seca ou excedente de chuva na BHI, com o domínio absoluto da normali-

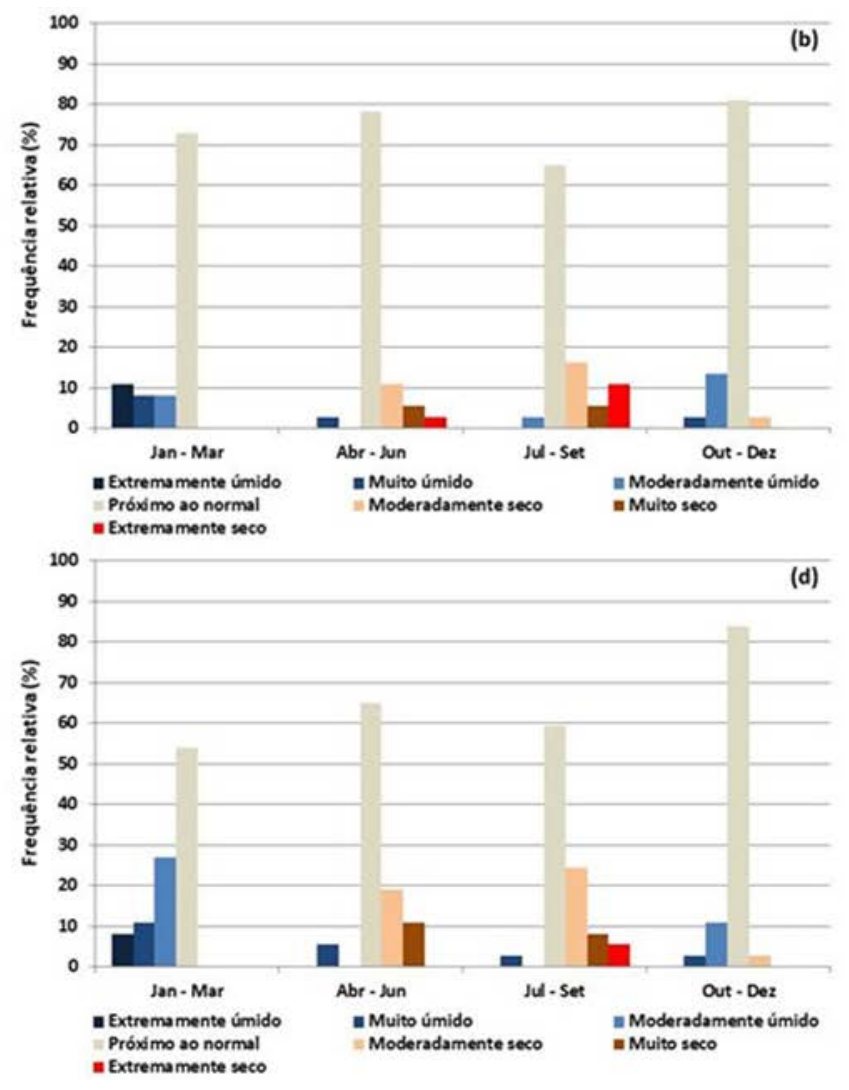

Figura 7 - Frequência relativa (\%) do índice SPI-3 para as localidades de Joaquim Távora (a), Piraí do Sul - Capinzal (b), São João da Boa Vista (c) e Doutor Ulysses (d). 

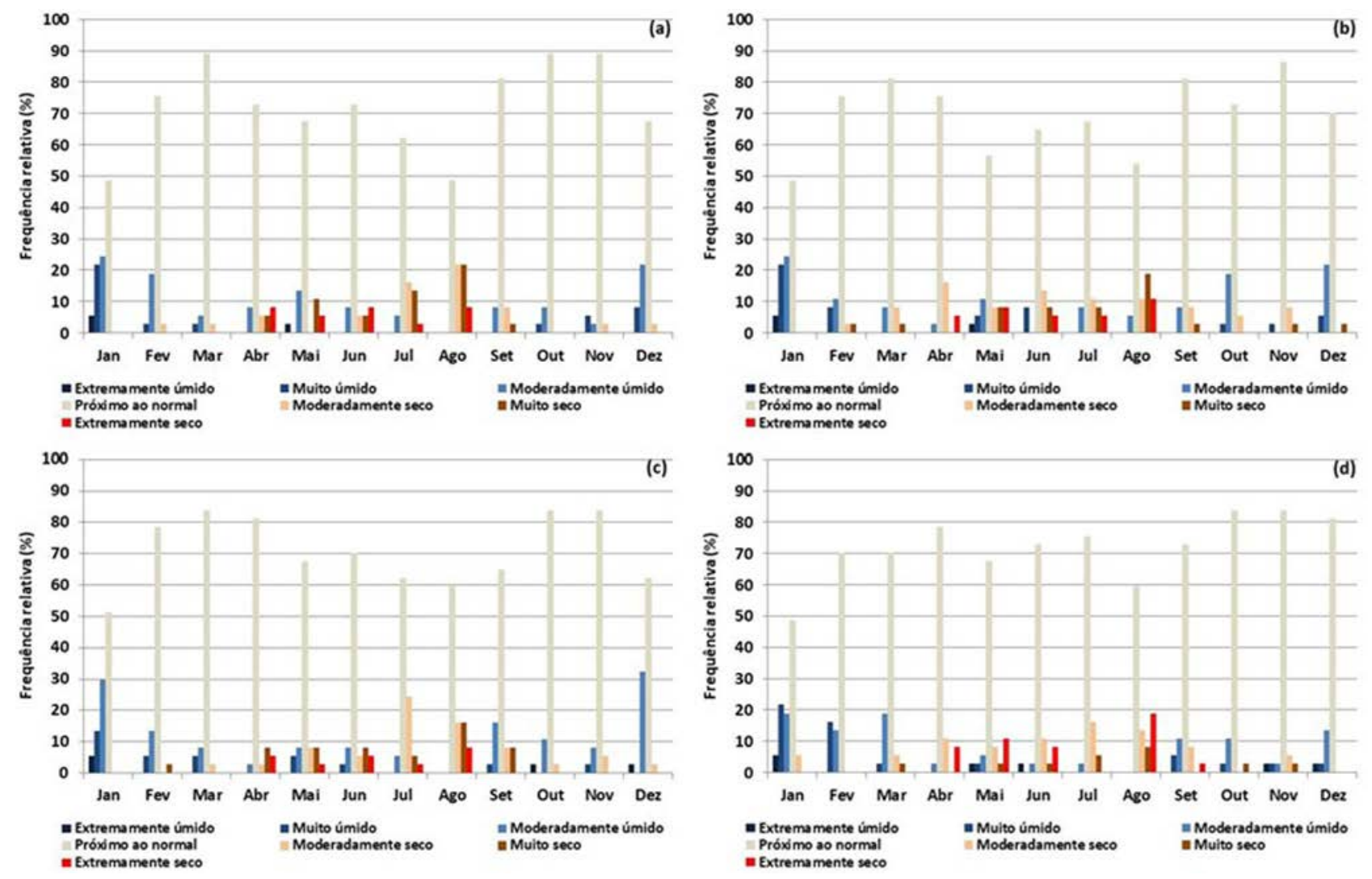

Figura 8 - Frequência relativa (\%) do índice SPI-1 para as localidades de JoaquimTávora (a), Piraí do Sul - Capinzal (b), São João da Boa Vista (c) e Doutor Ulysses (d).

dade. O período entre janeiro e março (verão) caracterizou-se pela maior frequência de períodos denominados entre "moderadamente úmido" e "extremamente úmido" $(>0,99)$, com aproximadamente $32 \%$ classificados nestas categorias. Inversamente, o inverno (julho a setembro) obteve o domínio de períodos secos $(>-0,99)$, equivalente a $34,9 \%$, e com raros registros superiores a 1,00 . Entre outubro e dezembro (primavera), a BHI caracteriza-se pela maior frequência de períodos de normalidade $(83,6 \%)$ e nenhum período "extremamente seco" ou "muito seco". O outono (abril a junho) obteve o predomínio da normalidade $(72 \%)$ e, comparativamente a primavera, apresenta mais registros de secas, com classes entre "moderadamente seco" e "muito seco" correspondendo a $22,2 \%$ do período em análise (Tabela 4).

Estes resultados permitiram constatar que a área de estudo, embora não se caracterize por reduções expressivas das chuvas, a frequência relativa do SPI-3 mostrou os períodos de maiores riscos à ocorrência de secas em suas diferentes categorias. Verifica-se que o padrão temporal de SPI-3 para a área em estudo é similar ao verificado por Oliveira-Júnior et al. (2017) para o Parque Nacional de Itatiaia juntamente a maior ocorrência de focos de incêndio no período entre julho e setembro. Nota-se que as diferenças entre as frequências relativas do SPI-3 entre os postos pluviométricos não foram expressivas e não permitem estabelecer padrões temporais deste índice para a BHI (Tabela 4).

O período de janeiro a março apresentou a maior frequência de períodos úmidos, enquanto que de julho a setembro destaca-se o aumento da ocorrência de secas de diferentes intensidades. Demonstra-se que as maiores frequências de meses denominados de próximo ao normal ocorrem nos meses de outono e primavera, o que representa a transição sazonal própria da dinâmica climática da região na qual se situa a área em estudo. Ressalta-se que janeiro apresentou o maior percentual de registros nas categorias úmidas $(\geq 0,99)$, pois corresponde ao mês de maior chuva média $(218,3 \mathrm{~mm})$ na BHRI, enquanto que em agosto ocorreu a maior frequência de categorias secas $(\leq 0,99)$, em função do menor registro de chuva (60,3 mm) -(Fig. 8).

Os resultados descritos acima são próximos aos obtidos por Terassi et al. (2018) para a RNPR, posto que estes autores identificaram a maior frequência de meses mais secos entre abril e setembro, enquanto que nos meses de verão predominaram as classes mais úmidas do SPI. Notou-se o predomínio da frequência da normalidade em todos os meses, especialmente para a primavera e para o outono. Estas características de distribuição temporal do 
Tabela 4 - Frequência relativa (\%) do SPI-3 para a BHRI.

\begin{tabular}{|c|c|c|c|c|c|c|c|c|c|c|c|c|c|c|}
\hline \multirow[t]{2}{*}{ Categorias } & \multicolumn{14}{|c|}{ Postos pluviométricos e estação meteorológica ${ }^{*}$} \\
\hline & 01 & 02 & 03 & 04 & 05 & $06^{*}$ & 07 & 08 & 09 & 10 & 11 & 12 & 13 & 14 \\
\hline \multicolumn{15}{|c|}{ Verão (janeiro a março) } \\
\hline Extremamente úmido & 8,1 & 8,1 & 8,1 & 10,8 & 10,8 & 10,8 & 10,8 & 10,8 & 10,8 & 10,8 & 16,2 & 10,8 & 10,8 & 10,8 \\
\hline Muito úmido & 10,8 & 0,0 & 10,8 & 8,1 & 8,1 & 5,4 & 8,1 & 8,1 & 10,8 & 10,8 & 2,7 & 5,4 & 8,1 & 13,5 \\
\hline Moderadamente úmido & 8,1 & 24,3 & 27,0 & 16,2 & 16,2 & 16,2 & 8,1 & 8,1 & 13,5 & 5,4 & 10,8 & 13,5 & 13,5 & 16,2 \\
\hline Próximo ao normal & 73,0 & 62,2 & 54,1 & 62,2 & 62,2 & 67,6 & 73,0 & 73,0 & 64,9 & 73,0 & 70,3 & 67,6 & 67,6 & 56,8 \\
\hline Moderadamente seco & 0,0 & 5,4 & 0,0 & 2,7 & 2,7 & 0,0 & 0,0 & 0,0 & 0,0 & 0,0 & 0,0 & 2,7 & 0,0 & 2,7 \\
\hline Muito seco & 0,0 & 0,0 & 0,0 & 0,0 & 0,0 & 0,0 & 0,0 & 0,0 & 0,0 & 0,0 & 0,0 & 0,0 & 0,0 & 0,0 \\
\hline Extremamente seco & 0,0 & 0,0 & 0,0 & 0,0 & 0,0 & 0,0 & 0,0 & 0,0 & 0,0 & 0,0 & 0,0 & 0,0 & 0,0 & 0,0 \\
\hline \multicolumn{15}{|c|}{ Outono (abril a junho) } \\
\hline Extremamente úmido & 0,0 & 0,0 & 0,0 & 0,0 & 0,0 & 0,0 & 0,0 & 0,0 & 0,0 & 0,0 & 0,0 & 0,0 & 0,0 & 0,0 \\
\hline Muito úmido & 2,7 & 0,0 & 5,4 & 2,7 & 0,0 & 0,0 & 2,7 & 0,0 & 0,0 & 0,0 & 0,0 & 0,0 & 0,0 & 0,0 \\
\hline Moderadamente úmido & 2,7 & 2,7 & 0,0 & 0,0 & 2,7 & 8,1 & 0,0 & 5,4 & 0,0 & 2,7 & 2,7 & 2,7 & 2,7 & 2,7 \\
\hline Próximo ao normal & 78,4 & 70,3 & 64,9 & 70,3 & 75,7 & 75,7 & 78,4 & 70,3 & 75,7 & 73,0 & 73,0 & 73,0 & 64,9 & 73,0 \\
\hline Moderadamente seco & 2,7 & 16,2 & 18,9 & 13,5 & 18,9 & 8,1 & 10,8 & 16,2 & 18,9 & 16,2 & 13,5 & 13,5 & 18,9 & 16,2 \\
\hline Muito seco & 10,8 & 5,4 & 10,8 & 10,8 & 0,0 & 5,4 & 5,4 & 8,1 & 2,7 & 5,4 & 8,1 & 8,1 & 13,5 & 5,4 \\
\hline Extremamente seco & 2,7 & 5,4 & 0,0 & 2,7 & 2,7 & 2,7 & 2,7 & 0,0 & 2,7 & 2,7 & 2,7 & 2,7 & 0,0 & 2,7 \\
\hline \multicolumn{15}{|c|}{ Inverno (julho a setembro) } \\
\hline Extremamente úmido & 0,0 & 0,0 & 0,0 & 0,0 & 0,0 & 0,0 & 0,0 & 0,0 & 0,0 & 0,0 & 0,0 & 0,0 & 0,0 & 0,0 \\
\hline Muito úmido & 0,0 & 0,0 & 2,7 & 0,0 & 0,0 & 0,0 & 0,0 & 0,0 & 0,0 & 0,0 & 0,0 & 0,0 & 0,0 & 0,0 \\
\hline Moderadamente úmido & 0,0 & 5,4 & 0,0 & 2,7 & 0,0 & 0,0 & 2,7 & 10,8 & 0,0 & 0,0 & 2,7 & 5,4 & 2,7 & 2,7 \\
\hline Próximo ao normal & 64,9 & 64,9 & 59,5 & 67,6 & 67,6 & 59,5 & 64,9 & 59,5 & 54,1 & 64,9 & 59,5 & 59,5 & 67,6 & 59,5 \\
\hline Moderadamente seco & 16,2 & 16,2 & 24,3 & 13,5 & 10,8 & 18,9 & 16,2 & 8,1 & 13,5 & 13,5 & 18,9 & 16,2 & 8,1 & 18,9 \\
\hline Muito seco & 2,7 & 2,7 & 8,1 & 5,4 & 8,1 & 8,1 & 5,4 & 8,1 & 21,6 & 5,4 & 8,1 & 2,7 & 13,5 & 5,4 \\
\hline Extremamente seco & 16,2 & 10,8 & 5,4 & 10,8 & 13,5 & 13,5 & 10,8 & 13,5 & 10,8 & 16,2 & 10,8 & 16,2 & 8,1 & 13,5 \\
\hline \multicolumn{15}{|c|}{ Primavera (outubro a dezembro) } \\
\hline Extremamente úmido & 0,0 & 0,0 & 0,0 & 0,0 & 5,4 & 2,7 & 0,0 & 0,0 & 0,0 & 2,7 & 0,0 & 2,7 & 0,0 & 0,0 \\
\hline Muito úmido & 8,1 & 0,0 & 2,7 & 2,7 & 5,4 & 2,7 & 2,7 & 2,7 & 5,4 & 5,4 & 8,1 & 2,7 & 8,1 & 10,8 \\
\hline Moderadamente úmido & 2,7 & 16,2 & 10,8 & 13,5 & 0,0 & 18,9 & 13,5 & 13,5 & 16,2 & 8,1 & 8,1 & 10,8 & 5,4 & 2,7 \\
\hline Próximo ao normal & 89,2 & 83,8 & 83,8 & 83,8 & 89,2 & 75,7 & 81,1 & 83,8 & 78,4 & 83,8 & 83,8 & 83,8 & 83,8 & 86,5 \\
\hline Moderadamente seco & 0,0 & 0,0 & 2,7 & 0,0 & 0,0 & 0,0 & 2,7 & 0,0 & 0,0 & 0,0 & 0,0 & 0,0 & 2,7 & 0,0 \\
\hline Muito seco & 0,0 & 0,0 & 0,0 & 0,0 & 0,0 & 0,0 & 0,0 & 0,0 & 0,0 & 0,0 & 0,0 & 0,0 & 0,0 & 0,0 \\
\hline Extremamente seco & 0,0 & 0,0 & 0,0 & 0,0 & 0,0 & 0,0 & 0,0 & 0,0 & 0,0 & 0,0 & 0,0 & 0,0 & 0,0 & 0,0 \\
\hline
\end{tabular}

índice SPI-1 e SPI-3 atestam o padrão sazonal das chuvas para este setor de transição climática entre o tropical do Brasil Central e do Subtropical do Brasil Meridional (Silva et al., 2006; Zandonadi et al., 2015) e, sobretudo, aumentam a atenção aos riscos decorrentes da seca meteorológica para o outono e inverno na BHRI.

\section{Conclusões}

A reduzida variabilidade interanual das chuvas devese às características do clima subtropical do Sul do Brasil, condição determinante na vertente paranaense da bacia hidrográfica do rio Itararé para ocorrência superior a $70 \%$ da categoria próximo ao normal na série temporal do SPI.
Isso mostra que este índice não possibilita a identificação das maiores alterações das chuvas associadas aos eventos mais significativos e intensos de ENOS. Entretanto, como se trata de uma região de transição climática entre dois domínios climáticos, a redução das chuvas ocasiona um aumento acentuado de secas no inverno, característica inerente ao clima tropical.

A utilização do índice SPI para diferentes escalas na vertente paranaense na bacia hidrográfica do rio Itararé permite identificar que a escala anual do SPI tem o predomínio da categoria próximo ao normal, enquanto as escalas mensal e trimestral mostram com maior acurácia os trimestres e os meses de maior susceptibilidade às secas na vertente paranaense da BHRI. O período entre abril e 
setembro (outono e inverno) apresenta a maior frequência relativa das categorias de seca, enquanto a primavera (outubro a dezembro) tem a maior predominância da normalidade e o verão caracteriza-se pela maior frequência de meses "moderadamente" a "extremamente úmidos".

\section{Agradecimentos}

O presente trabalho foi realizado com apoio do Programa Nacional de Cooperação Acadêmica da Coordenação de Aperfeiçoamento de Pessoal de Nível Superior - Edital CAPES 071/2013 - Processo nº88881.068465/2014-01. Os autores agradecem a Coordenação de Aperfeiçoamento de Pessoal de Nível Superior pela concessão das bolsas de Doutorado, Pós-Doutorado e Mestrado ao primeiro, terceiro e quinto autores, nesta ordem. Agradecimentos ao Conselho Nacional de Desenvolvimento Científico e Tecnológico pela Bolsa de Produtividade em Pesquisa - Nível 2 e 1D concedidas ao segundo autor (306410/2015-0) e quarto autor (303676/2013-2).

\section{Referências}

AGNEW, C.T. Using the SPI to identify drought. Drought Network News, v. 12, n. 1, p. 6-12, 2000

ÁlVARES, C.A.; STAPE, J.L.; SENTELHAS, P.C.; DE MORAES GONÇALVES, J.L.; SPAROVEK, G. Köppen's climate classification map for Brazil. Meteorologische Zeitschrift, v. 22, n. 6, p. 711-728, 2013.

BLAIN, G.C.; PEZZOPANE, J.R.M.; PEZZOPANE, J.E.M.; BONOMO, R. Índice de precipitação aplicado às condições de seca no estado do Espírito Santo. Revista Brasileira de Engenharia Agrícola e Ambiental, v. 14, n. 10, p. 10671073, 2010

BLAIN, G.C.; KAYANO, M.T. 118 anos de dados mensais do Índice Padronizado de Precipitação: série meteorológica de Campinas, Estado de São Paulo. Revista Brasileira de Meteorologia, v. 26, n. 1, p. 137-148, 2011.

BLAIN, G.C. Extreme value theory applied to the standardized precipitation index. Acta Scientiarum Technology, v. 36, n. 1, p. 147-155, 2013.

BORSATO, V.A.; MENDONÇA, F.A. Participação da massa polar atlântica na dinâmica dos sistemas atmosféricos no Centro Sul do Brasil. Mercator, v. 14, n. 1, p. 113-130, 2015.

CÂNDIDO, D.H.; NUNES, L.H. Influência da orografia na precipitação da área entre o vale do rio Tietê e a Serra da Mantiqueira. Geousp, v. 1, n. 24, p. 8-27, 2008.

CARMELLO, V.; SANT'ANNA NETO, J.L. Rainfall Variability and Soybean Yield in Paraná State, Southern Brazil. International Journal of Environmental \& Agriculture Research, v. 2, n. 1, p. 86-97, 2016.

CAVIGLIONE, J.H.; KIIHL, L.R.B.; CARAMORI, P.H.; OLIVEIRA, D. Cartas climáticas do Paraná. Londrina: IAPAR, 2000. CD ROM.
CHIERICE, R.A.F.; LANDIM, P.M.B. Variabilidade espacial e temporal de precipitação pluviométrica na bacia hidrográfica do rio Mogi Guaçu. Geociências, v. 33, n. 1, p. 157171, 2014.

CLARKE, R.T.; SILVA, B.C. Análise estatística de chuvas intensas na bacia do rio São Francisco. Revista Brasileira de Meteorologia, v. 19, n. 3, p. 265-272, 2004.

CARDOZO, A.B.; REBOITA, M.S.; GARCIA, S.R. Climatologia de Frentes Frias na América do Sul e sua relação com o Modo Anular Sul. Revista Brasileira de Climatologia, v. 17, n. 1, p. 9-29, 2015.

CORREA, M.G.G.; GALVANI, E. Variabilidade espacial e sazonal da precipitação pluviométrica na bacia hidrográfica do rio Piquiri - PR. Revista do Departamento de Geografia da USP, v. 34, n. 1, p. 21-30, 2017.

DAI, A. Drought under global warming: A review. Wiley Interdisciplinary Reviews: Climate Change, v. 2, n. 1, p. 4565, 2011.

DUBREUIL, V.; FANTE, K.P.; PLACHON, O.; SANT'ANNA NETO, J.L. Les types de climats annuels au Brésil: une application de la classification de Köppen de 1961 à 2015. EchoGéo, v. 3, n. 41, p. 1-27, 2017.

FECHINE, J.A.L. Identificação de secas meteorológicas na região metropolitana de Fortaleza, usando o índice de precipitação padronizada (SPI). Boletim de Geografia, v. 33, n. 2, p. 18-33, 2015.

FERNANDES, D.S.; HEINEMANN, A.B.; PAZ, R.L.F.; AMORIM, A.O. Desempenho de índices quantitativos de seca na estimativa da produtividade de arroz de terras altas. Pesquisa Brasileira Agropecuária, v. 45, n. 8, p. 771-779, 2010.

FRITZSONS, E.; MANTOVANI, L.E.; WREGE, M.S.; CHAVES NETO, A. Análise da pluviometria para definição de zonas homogêneas no estado do Paraná. RA'E GA: o Espaço Geográfico em Análise, v. 23, n. 1, p. 555-572, 2011.

GANAPATHI, H. Assessment of drought severity using Standard Precipitation Index in Ahmednagar district, India. International Research Journal of Engineering and Technology, v. 5, n. 5, p. 1777-1780. 2018.

GIDDINGS, L.; SOTO, M.; RUTHERFORD, B.M.; MAAROUF, A. Standardized Precipitation Index Zones for México. Atmósfera, v. 18, n. 1, p. 33-56, 2005.

GOIS, G.; DELGADO, R.C.; OLIVEIRA-JÚNIOR, J.F. Modelos teóricos transitivos aplicados na interpolação espacial do standardized precipitation index (SPI) para os episódios de El Niño Forte no Estado do Tocantins, Brasil. Irriga, v. 20, n. 2, p. 371-387, 2015.

GRIMM, A.M.; FERRAZ, S.E.T.; GOMES, J. Precipitation anomalies in southern Brazil associated with El Niño and La Niña Events. Journal of Climate, v. 11, n. 1, p. 2863 2880, 1998.

GRIMM, A.M.; BARROS, V.R.; DOYLE, M.E. Climate variability in Southern South America associated with El Niño and La Niña events. Journal of Climate, v. 13, n. 1, p. 3558, 2000.

GUEDES, R.V.S.; MACEDO, M.J.H.; SOUSA, F.A.S. Análise espacial de eventos de secas com base no índice padronizado de precipitação e análise de agrupamento. Revista Brasileira de Ciências Ambientais, v. 1, n. 23, p. 55-65, 2012. 
HAYES, M.J. Revisiting the SPI: clarifying the process. Drought Network News, v. 12, n. 1, p. 13-14, 1999.

HUGHES, B.L.; SAUNDERS, M.A.A. Drought Climatology for Europe. International Journal of Climatology, v. 22, n. 13, p. 1571-1592, 2002.

KELLER FILHO, T.; ASSAD, E.D.; LIMA, P.R.S.R. Regiões pluviometricamente homogêneas no Brasil. Pesquisa Brasileira Agropecuária, v. 40, n. 4, p. 311-322, 2005.

KIM, C.J.; PARK, M.J.; LEE J.H. Analysis of climate change impacts on the spatial and frequency patterns of drought using a potential drought hazard mapping approach. International Journal of Climatology, v. 34, n. 1, p. 61-80, 2014.

KOMUSCU, A.U. Using the SPI to analyze spatial and temporal patterns of drought in Turkey. Drought Network News, Lincoln, v. 11, n. 1, p. 7-13, 1999.

LI, W.; FU, R.; JUAREZ, N.; FERNANDES, K. Observed change of the standardized precipitation index, its potential cause and implications to future climate change in the Amazon region. Philosophical Transactions of The Royal Society, v. 363, n. 1498, p. 1767-1772, 2008.

LYRA, G.B.; OLIVEIRA-JÚNIOR, J.F.; GOIS, G.; CUNHAZERI, G.; ZERI, M. Rainfall variability over Alagoas under the influences of SST anomalies. Meteorology and Atmospheric Physics, v. 129, n. 2, p. 157-171, 2017.

NASCIMENTO, F.C.A.; BRAGA, C.C.; ARAÚJO, F.R.C.D. Análise estatística dos eventos secos e chuvosos de precipitação no estado do Maranhão. Revista Brasileira de Meteorologia, v. 32, n. 3, p. 375-386, 2017.

NASCIMENTO JÚNIOR, L.; SANT'ANNA NETO, J.L. Contribuição aos estudos da precipitação no estado do Paraná: a oscilação decadal do Pacífico - ODP. RA'E GA: o Espaço Geográfico em Análise, v. 35, n. 1, p. 314-343, 2016.

McKEE, T.B.; DOESKEN, N.J.; KLEIST, J. The relationship of drought frequency and duration to times scale. In: VIII Conference on Applied Climatology. Boston. American Meteorological Society, p. 179-184, 1993.

MISHRA, A.K.; SINGH, V.P. A review of drought concepts. Journal of Hydrology, v. 391, n. 1-2, p. 202-216, 2010.

NOAA/CPC - National Oceanic and Atmospheric Administration/Climate Prediction Center. EI Niño/Southern Oscillation (ENSO). Disponível em: http://www.cpc.ncep. noaa. gov/products/analysis_monitoring/ensostuff/ensoyears. shtml. Acesso em 17/07/2016.

NERY, J.T.; STIVARI, S.M.S.; MARTINS, M.L.O.F.; SILVA, E.S.; SOUSA, P. Estudo da precipitação do estado do Paraná e sua associação à temperatura da superfície do Oceano Pacífico. Revista Brasileira de Agrometeorologia, v. 13, n. 1, p. 161-171, 2005.

NERY, J.T. Dinâmica climática da região Sul do Brasil. Revista Brasileira de Climatologia, v. 1, n. 1, p. 61-75, 2006.

NERY, J.T.; CARFAN, A.C. Re-analysis of pluvial precipitation in southern Brazil. Atmósféra, v. 27, n. 2, p. 103-114, 2014.

OLIVEIRA-JÚNIOR, J.F.; LYRA, G.B.; GOIS, G.; BRITO, T.T.; MOURA, N.S.H. Análise de homogeneidade de séries pluviométricas para determinação do índice de seca IPP no estado de Alagoas. Floresta e Ambiente, v. 19, n. 2, p. 101-112, 2012.
OLIVEIRA-JÚNIOR, J.F.; SOUSA, G.; NUNES, M.; FERNANDES, M.; TOMZHINSKI, G. Relação Entre o Standardized Precipitation Index (SPI) e os Relatórios de Ocorrência de Incêndios (ROI) no Parque Nacional do Itatiaia. Floresta e Ambiente, v. 24, n. 1, p. 1-9, 2017.

OLIVEIRA-JUNIOR, J.F.; GOIS, G.; TERASSI, P.M.B.; SILVA JÚNIOR, C.A.; BLANCO, C.J.C.; SOBRAL, B.S.; GASPARINI, K.A.C. Drought severity based on the SPI index and its relation to the ENSO and PDO climatic variability modes in the regions North and Northwest of the State of Rio de Janeiro - Brazil. Atmospheric Research, v. 212, n. 1, p. 91-105, 2018.

PELLEGATTI, C.H.G.; GALVANI, E. Avaliação da precipitação na Serra do Mar - SP eventos de diferentes intensidade e duração. Geousp, v. 13, n. 27, p. 132-148, 2010.

PENALBA, O.C.; RIVERA, J.A. Precipitation response to El Niño/La Niña events in Southern South America - emphasis in regional drought occurrences. Advances in Geosciences, v. 42, n. 1, p. 1-14, 2015.

RAJSEKHAR, D.; SINGH, V.P.; MISHRA A.K. Multivariate drought index: An information theory based approach for integrated drought assessment. Journal of Hydrology, v. 526, n. 1, p. 164-182, 2015.

REBOITA, M.S.; GAN, M.A.; ROCHA, R.P.; AMBRIZZI, T. Regimes de precipitação na América do Sul. Revista Brasileira de Meteorologia, v. 25, n. 2, p. 185-204, 2010.

RIVERA, J.A.; PENALBA, O.C. Trends and spatial patterns of drought affected area in Southern South America. Climate, v. 2, n. 4, p. 264-278, 2014.

SANTOS, S.R.Q.; BRAGA, C.C.; SANTOS, A.P.P.; BRITO, J.I.B.; CAMPOS, T.L.O.B. Classificação de eventos extremos de precipitação em múltiplas escalas de tempo em Belém-PA: Utilizando o índice de precipitação normalizada. Revista Brasileira de Geografia Física, v. 7, n. 4, p. 628-635, 2014.

SANTOS, S.R.Q.; BRAGA, C.C.; SANSIGOLO, C.A.; SANTOS, A.P.P. Determinação de regiões homogêneas do índice de precipitação normalizada (SPI) na Amazônia Oriental. Revista Brasileira de Meteorologia, v. 32, n. 1, p. 111-122, 2017.

SEILER, R.A.; HAYES, M.; BRESSAN, L. Using the standardized precipitation index for flood risk monitoring. Internacional Journal of Climatology, v. 22, n. 11, p. 13651376, 2002.

SILVA, C.B.; SANT'ANNA NETO, J.L.; TOMMASELLI, J.T.G.; PASSOS, M.M. Dinâmica atmosférica e análise geoestatística do clima na área de integração paisagística 'Raia Divisória' SP/PR/MS: uma proposta de tipologia climática. Revista Brasileira de Climatologia, v. 2, n. 1, p. 53-70, 2006.

SILVA, W.L.; DERECZYNSKI, C.; CHANG, M.; FREITAS, M.; MACHADO, B.J.; TRISTÃO, L.; RUGGERI, J. Tendências observadas em indicadores de extremos climáticos de temperatura e precipitação no Estado do Paraná. Revista Brasileira de Meteorologia, v. 30, n. 2, p. 181194, 2015.

SIRDAS, S.; SEN, Z. Spatio-temporal drought analysis in the Trakya region, Turkey. Hydrological Sciences Journal, v. 48 , n. 5, p. 809-820, 2004. 
SILVA, C.B.; SANT'ANNA NETO, J.L.; TOMMASELLI, J.T.G.; PASSOS, M.M. Dinâmica atmosférica e análise geoestatística do clima na área de integração paisagística 'Raia Divisória' SP/PR/MS: uma proposta de tipologia climática. Revista Brasileira de Climatologia, v. 2, n. 1, p. 53-70, 2006.

SOBRAL, B.S.; OLIVEIRA-JÚNIOR, J.F.; GOIS, G.; PEREIRA-JÚNIOR, E.R. Spatial variability of SPI and RDIst drought indices applied to intense episodes of drought occurred in Rio de Janeiro State - Brazil. International Journal of Climatology, v. 38, n. 10, p. 3896-3916, 2018.

SOUSA, F.A.S.; MACEDO, M.J.H.; GUEDES, R.V.S.; SILVA, V.P.R. O Índice de Precipitação Padronizada (IPP) na identificação de extremos de chuvas e secas na bacia do rio Paraguaçu. Ambiência, v. 12, n. 2, p. 707-719, 2016.

SPINONI, J.; NAUMANN, G.; CARRAO, H.; BARBOSA, P.; VOGT, J. World drought frequency, duration, and severity for 1951-2010. International Journal of Climatology, v. 34, n. 8, p. 2792-2804, 2014.

TEDESCHI, R.G.; GRIMM, A.M.; CAVALCANTI, I.F. Influence of Central and East ENSO on extreme events of precipitation in South America during austral spring and summer. International Journal of Climatology, v. 35, n. 8, p. 2045-2064, 2015.

TEODORO, P.E.; CORRÊA, C.C.G.; TORRES, F.E.; OLIVEIRA JÚNIOR, J.F.; SILVA JÚNIOR, C.A.; GOIS, G.; DELGADO, R.C. Analysis of the occurrence of wet and drought periods using Standardized Precipitation Index in Mato Grosso do Sul State, Brazil. Journal of Agronomy, v. 14, n. 2, p. 80-86, 2015.

TERASSI, P.M.B.; TOMMASELLI, J.T.G. Caracterização termo-pluviométrica e a classificação climática para a vertente paranaense da bacia hidrográfica do rio Itararé. Formação, v. 2, n. 22, p. 169-191, 2015.

TERASSI, P.M.B.; GRAÇA, C.H.; TOMMASELLI, J.T.G. Características da precipitação pluvial e a erosividade das chuvas na vertente paranaense da bacia hidrográfica do rio Itararé. Revista do Departamento de Geografia, v. 31, n. 1, p. 118-131, 2016.

TERASSI, P.M.B.; GALVANI, E. Identification of homogeneous rainfall regions in the eastern watersheds of the State of Paraná. Climate, v. 5, n. 1, p. 53-65, 2017.
TERASSI, P.M.B.; TOMMASELLI, J.T.G. Zoneamento de parâmetros climáticos para a vertente paranaense da bacia hidrográfica do rio Itararé. GeoUerj, v. 31, n. 1, p. 417-438, 2017.

TERASSI, P.M.B.; SILVEIRA, H.; GRAÇA, C.H.; OLIVEIRAJÚNIOR, J.F. Variabilidade pluviométrica e a erosividade das chuvas na Unidade Hidrográfica Pirapó, Paranapanema III e IV - Paraná. RA'E GA: o Espaço Geográfico em Análise, v. 39, n. 1, p. 76-91, 2017.

TERASSI, P.M.B.; OLIVEIRA-JÚNIOR, J.F.; GOIS, G.; GALVANI, E. Variabilidade do Índice de Precipitação Padronizada na Região Norte do Estado do Paraná Associada aos Eventos de El Niño-Oscilação Sul. Revista Brasileira de Meteorologia, v. 33, n. 1, p. 11-25, 2018.

TURKES, M.; TATLI, H. Use of the standardized precipitation index (SPI) and a modified SPI for shaping the drought probabilities over Turkey. International Journal of Climatology, v. 29, n. 15, p. 2270-2282, 2009.

WREGE, M.S.; FRITZSONS, E.; CARAMORI, P.H.; RICCE, W.S.; RADIN, B.; STEINMETZ, S.; REISSER JÚNIOR, C. Regiões com similaridade de comportamento hídrico no Sul do Brasil. RA'E GA: o Espaço Geográfico em Análise, v. 38, n. 1, p. 363-382, 2016.

ZANDONADI, L.; ACQUAOTTA, F.; FRATIANNI, S.; ZAVATTINI, J.A. Changes in precipitation extremes in Brazil (Paraná River Basin). Theoretical and Applied Climatology, v. 119, n. 1, p. 741-756, 2015.

ZENG, N.; YOON, J.H.; MARENGO, J.A.; SUBRAMANIAM, A.; NOBRE, C.A.; MARIOTTI, A.; NEELIN, J.D. Causes and impacts of the 2005 Amazon drought. Environmental Research Letters, v. 3, n. 1, p. 1-9, 2008.

ZHANG, Q.; XU, C.; ZHANG, Z. Observed changes of drought/ wetness episodes in the Pearl River basin, China, using the standardized precipitation index and aridity index. Theoretical and Applied Climatology, v. 98, n. 1-2, p. 89-99, 2009.

License information: This is an open-access article distributed under the terms of the Creative Commons Attribution License (type CC-BY), which permits unrestricted use, distribution and reproduction in any medium, provided the original article is properly cited. 